\title{
Comparative analysis of diet and tobacco use among households in Bangladesh
}

Mandeep Virk-Baker', Muhammad Jami Husain², Mark Parascandola ${ }^{1}$

\begin{abstract}
INTRODUCTION While studies from developed countries have reported dietary differences between tobacco users and non-users, less is known about the influence of tobacco on diet in developing countries where malnutrition is a major public health challenge.

METHODS In this study we used the nationally representative Household Income Expenditure Survey 2010 from Bangladesh. Detailed household-level food consumption data including both ethnic and region-specific foods were collected over 14 days, consisting of 7 visits each collecting two days of dietary recall information.

RESULTS Out of 12240 households, 2061 consumed smoking tobacco only (16.8\%), 3284 consumed smokeless tobacco only $(26.8 \%)$, and 3348 consumed both (27.4\%). Overall, $71 \%$ of the households reported expenditure on tobacco (smoking and/or smokeless) and were considered any-tobacco use households. Our results indicate that after controlling for household expenditure, household size, household child to adult ratio, place of residence (urban/rural), and region fixed effects, any-tobacco households consumed significantly lower amounts (g/ day) of milk and dairy products $(\beta=-17.11, \mathrm{p}<0.01)$ and oil/fat $(\beta=-10.30$, $\mathrm{p}<0.01)$ compared to tobacco non-use households $(\beta$ : adjusted mean difference in food amount $\mathrm{g} /$ day/household). Conversely, consumption of cereal grains ( $\beta$ $=152.46, \mathrm{p}<0.0001)$ and sugar $(\beta=8.16, \mathrm{p}<0.0001)$ were significantly higher among any-tobacco households compared to non-tobacco households. We observed similar patterns for smoking-only, smokeless-only, and dual tobacco product households.

CONCLUSION Evidence of dietary differences between tobacco-use and non-use households may play an important role in developing strategies to address poor diet and malnutrition among tobacco-use households in a developing country like Bangladesh. This study provides one of the first reports addressing diet in relation to tobacco use from a developing country, particularly using nationally representative data. The finding that tobacco-use households have poorer dietary consumption than non-use households suggests that it is important to address tobacco use in the context of nutrition and development programs in low-income environments.
\end{abstract}

\section{AFFILIATION}

1 US National Cancer Institute, Bethesda, United States 2 Centers for Disease Control and Prevention, Atlanta, United States

CORRESPONDENCE TO

Mark Parascandola. US National Cancer Institute, 9609 Medical Center Drive, Bethesda, MD 20892-9761, United States E-mail: paramark@mail.nih.gov

\section{KEYWORDS}

socioeconomic factors, nutrition smokeless tobacco

Received: 29 October 2018 Revised: 10 December 2018 Accepted: 13 March 2019

\section{INTRODUCTION}

Studies from developed countries have reported dietary differences between tobacco smokers and non-smokers. Several studies conducted in North America $^{1-6}$ suggest that, compared with non-smokers, smokers have lower intake of citrus fruit, total fruit, 
vegetables, dietary fiber and dietary antioxidants including lower intake of dietary beta-carotene, vitamin $\mathrm{E}$, vitamin $\mathrm{C}$, and folate. At the same time, higher intake of alcohol, coffee, processed meat, dietary fat and total calories has been observed among smokers compared to non-smokers. Similarly, studies from Europe ${ }^{7,8}$ reported that smokers have lower intake of fruit, vegetables, dietary fiber and dietary antioxidants but higher intake of coffee, alcohol and butter/margarine compared to non-smokers. These dietary patterns, characterized by lower consumption of plant-based foods and higher consumption of dietary fat and meat, have been associated with increased risk for coronary heart disease and cancer.

However, most epidemiological evidence for a poor diet among tobacco users is primarily limited to cigarette smoking in high-income countries. Less is known about the relationship between tobacco use, especially smokeless tobacco use, and dietary patterns among populations in developing countries. In a low-income setting, limited resources may result in money being diverted from basic necessities, including food, to tobacco purchasing thus reducing dietary quality and contributing to malnutrition ${ }^{9}$. Combating malnutrition in developing countries is a major global public health priority; expenditure on tobacco has been shown to exacerbate poverty and malnutrition by competing for the limited resources $^{10-12}$.

Bangladesh is among the highest tobacco consuming countries in the world, with over $43.3 \%$ of adults (around 41.3 million people) using tobacco products in 2009 (21.9 million using smoking tobacco and 25.9 million using smokeless tobacco $)^{13}$. Additionally, in $2012,17.3 \%$ of the population (26.5 million) in Bangladesh was malnourished ${ }^{14}$. In this study, we used the nationally representative Household Income Expenditure Survey (HIES2010) from Bangladesh to assess the relationship between household expenditure on tobacco products and major food items. In Bangladesh, tobacco is used in a variety of forms, including cigarettes, bidis (hand rolled cigarettes) and a range of smokeless tobacco products. The specific objectives of this study were to analyze and compare consumption of major food categories, i.e. cereal grains, legumes and beans, fish, meat, milk, fruit, vegetable, sugar, eggs, oil/ fat, and beverages among tobacco-use (including smoking tobacco and smokeless tobacco) and nonuse households.

\section{METHODS}

\section{Data}

The most recent (2010) nationally representative Household Income and Expenditure Survey (HIES) from Bangladesh Bureau of Statistics (BBS) was used for the current study. Detailed HIES methodology and survey design were published previously ${ }^{15,16}$. The 2010 HIES consisted of 12240 households ( 7840 rural and 4400 urban). Part A of the HIES consumption module recorded household food quantities consumed and money spent on food items per day for 14 days (collected over 7 visits with a 2 -day recall for each visit). The dietary questionnaire included a comprehensive list of 194 foods including regionally available foods that were broadly categorized as: cereal grains products; legumes and beans; fish products; eggs, meat, and poultry; vegetables; milk and dairy products; sugar, molasses, and desserts; oil/fat; fruits; and beverages and other drinks. In Part B, weekly consumption of around 25 items and corresponding values were collected; these included items like spices, betel leaf and chew-goods, which are typically bought on a weekly basis. Appendix Table 1 provides detailed mapping between the broad food categories and HIES food items.

Consumption of and expenditure on tobacco and tobacco products, including cigarettes, tobacco leaf, bidis, and gul, were recorded in the Part A (daily) food consumption section, while some other smokeless products (e.g. betel leaf and chewgoods) were recorded in the Part B (weekly) food consumption section of the questionnaire. These tobacco products were grouped into smoking and smokeless categories for the purposes of our analysis. The survey also recorded expenditure data on a range of non-food items in Part C and Part D of the HIES consumption modules, including clothing, housing, education, health, energy and utilities, transport and entertainment etc.

The analyses presented in this paper are at the household level, i.e. a single household was used as the primary unit of analysis. A household was considered as a tobacco-use (any-tobacco) household if it recorded any consumption of tobacco. Households were further divided into 
Table 1. Sociodemographic characteristic of HIES households, by household tobacco-use status

\begin{tabular}{|c|c|c|c|c|c|}
\hline \multirow[t]{2}{*}{ Characteristics } & Non-use & Smoking only & Smokeless only & Dutal-tobacco & $\begin{array}{l}\text { Total number of } \\
\text { houscholds }\end{array}$ \\
\hline & $(n$, row \%) & $(n$, row $\%)$ & $(n$, row $\%)$ & $(n$, row \% $)$ & $(n$, row \% $)$ \\
\hline All households & 3547 (29) & 2061 (17) & $3284(27)$ & 3348 (27) & $12240(100)$ \\
\hline \multicolumn{6}{|l|}{ Place of residence } \\
\hline Rural & 1940 (25) & $1267(16)$ & $2228(28)$ & 2405 (31) & $7840(100)$ \\
\hline Urban & 1607 (37) & 794 (18) & $1056(24)$ & $943(21)$ & $4400(100)$ \\
\hline \multicolumn{6}{|l|}{ Region } \\
\hline Barisal & $223(23)$ & $78(8)$ & $482(49)$ & $197(20)$ & $980(100)$ \\
\hline Chittagong & $532(24)$ & $255(12)$ & $634(29)$ & $779(35)$ & $2200(100)$ \\
\hline Dhaka & 1367 (39) & $620(18)$ & $712(20)$ & $841(24)$ & $3540(100)$ \\
\hline Khulna & $613(34)$ & $523(29)$ & 335 (19) & $329(18)$ & $1800(100)$ \\
\hline Rajshahi & $526(33)$ & 397 (25) & $327(21)$ & $330(21)$ & $1580(100)$ \\
\hline Rangpur & $224(18)$ & $136(11)$ & $487(38)$ & $433(34)$ & $1280(100)$ \\
\hline Sylhet & $62(7)$ & $52(6)$ & $307(36)$ & $439(51)$ & $860(100)$ \\
\hline \multicolumn{6}{|l|}{$\begin{array}{l}\text { At least one member suffering } \\
\text { from chronic disease }\end{array}$} \\
\hline No & $2213(34)$ & 1191 (19) & $1419(22)$ & $1597(25)$ & $6420(100)$ \\
\hline Yes & $1334(23)$ & $870(15)$ & $1865(32)$ & $1751(30)$ & $5820(100)$ \\
\hline Average household size & 4.01 & 4.41 & 4.49 & 5.11 & 4.50 \\
\hline Children to household size ratio & 0.25 & 0.26 & 0.20 & 0.23 & 0.23 \\
\hline
\end{tabular}

Calculations using Bangladesh HIES 2010.

the following mutually exclusive categories for analysis: smoking-only, smokeless-only, and dualtobacco use (smoking and smokeless product consumption) households. Dietary consumption data were categorized into 11 food groups: cereal grains, legumes and beans, fish, meat, milk, fruit, vegetable, sugar, eggs, oil/fat, and beverages.

\section{Statistical analyses}

Unadjusted comparisons for consumption (g/day/ household) of the respective food categories for anytobacco, smoking-only, smokeless-only and dualtobacco use households were analyzed using Student's t-test statistic from bivariate regressions. The adjusted multivariate regression analysis controlled for several potentially confounding variables including total household expenditure, household size, household children-adults composition, place of residence (urban vs rural), geographical region (Chittagong, Dhaka, Khulna, Rajshahi, Rangpur, Sylhet), and the presence of any member in the household suffering from chronic disease. All estimates were obtained using sampling weights for complex survey designs using Stata version $14^{17}$.

\section{RESULTS}

Out of 12240 households, 8693 (71\%) households reported any expenditure on tobacco and were considered tobacco using households: 2061 (16.8\%) consumed smoking-only tobacco (including bidis and cigarettes), 3284 (26.8\%) consumed smokeless-only tobacco, and 3348 (27.4\%) consumed both (dualtobacco use households). Further information on household tobacco-use status by place of residence and region, including household sociodemographic composition and chronic disease status, are presented in Table 1. For instance, while the percentage of households reporting smoking-only tobacco products is higher in urban than in rural households $(18 \%$ vs $16 \%$ ), the proportion of households consuming smokeless-only and dual-tobacco are higher in rural areas ( $28 \%$ and $31 \%$ vs $24 \%$ and $21 \%$, respectively).

\section{Unadjusted comparison of dietary intake}

As shown in Table 2, compared to the non-use households, any-tobacco households consumed significantly higher amount ( $\mathrm{g} /$ day) of cereal grains ( 2273 vs $1714, \mathrm{p}<0.01)$, fish (229 vs $211, \mathrm{p}<0.01)$, fruit $(212$ vs $180, \mathrm{p}<0.01)$ and sugar (64 vs 49 , 
Table 2. Unadjusted food group mean consumption ( $\mathrm{g}$ day per household) comparison between tobacco-use households and tobacco non-use households

\begin{tabular}{|c|c|c|c|c|c|}
\hline \multirow[t]{2}{*}{ Food group } & Non-use & Any-tobacco & Smoking only & Smokeless - only & Dual-tobacco \\
\hline & $\begin{array}{l}\text { Vean consumption } \\
\left(95^{\circ} \% \mathrm{CI}\right)\end{array}$ & \multicolumn{4}{|c|}{$\begin{array}{l}\text { Difference in consumption from the mean of non-use households } \\
\qquad(95 \% \mathrm{CI})\end{array}$} \\
\hline Cereal grains & $1714(1679,1749)$ & $558^{\mathrm{a}}(512,605)$ & $319^{\mathrm{a}}(262,375)$ & $430^{\mathrm{a}}(373,487)$ & $840^{\mathrm{a}}(771,908)$ \\
\hline $\begin{array}{l}\text { Legumes and } \\
\text { beans }\end{array}$ & $60.93(56.80,65.04)$ & $5.62^{\mathrm{c}}(1.08,10.16)$ & $1.33(-3.20,5.85)$ & $3.83(-1.69,9.35)$ & $10.18^{\mathrm{a}}(4.08,16.27)$ \\
\hline Fish & $211.16(202.88,219.43)$ & $17.75^{\mathrm{a}}(8.42,27.09)$ & $-6.49(-17.08,4.10)$ & $12.57^{b}(0.91,24.22)$ & $38.63^{\mathrm{a}}(26.17,51.08)$ \\
\hline Meat & $91.91(78.58,105.24)$ & $-2.54(-14.33,9.25)$ & $-6.73(-21.69,8.23)$ & $5.22(-6.86,17.31)$ & $-7.45(-21.42,6.53)$ \\
\hline Milk & $139.67(124.60,154.75)$ & $-0.34(-15.28,14.61)$ & $-14.98^{c}(-30.97,1.01)$ & $3.62(-14.61,21.86)$ & $5.29(-13.49,24.07)$ \\
\hline Fruit & $180(154,206)$ & $32.60^{\mathrm{a}}(8.88,56.31)$ & $15.86(-8.78,40.50)$ & $33.29^{b}(6.10,60.48)$ & $42.80^{b}(9.71,75.89)$ \\
\hline Vegetable & $1011(979,1043)$ & $174(138,209)$ & $95.91^{\mathrm{a}}(54.82,137)$ & $131^{\mathrm{a}}(90.46,172)$ & $266^{\mathrm{a}}(219,313)$ \\
\hline Sugar & $49.40(43.59,55.20)$ & $15.09^{a}(9.38,20.80)$ & $7.61^{\mathrm{b}}(0.79,14.43)$ & $14.56^{\mathrm{a}}(8.07,21.04)$ & $20.48^{\mathrm{a}}(12.83,28.13)$ \\
\hline Eggs & $28.33(26.18,30.48)$ & $-3.34^{b}(-6.10,-0.58)$ & $-2.87^{b}(-5.44,-0.31)$ & $-3.18^{c}(-6.98,0.62)$ & $-3.81^{c}(-8.08,0.47)$ \\
\hline Oil/fat & $97.64(94.02,101)$ & $-7.98^{\mathrm{a}}(-11.64,-4.33)$ & $-4.73^{b}(-9.13,-0.33)$ & $-9.15^{a}(-13.22,-5.08)$ & $-8.95^{a}(-13.28,-4.63)$ \\
\hline Beverage & $17.02(12.96,21.07)$ & $0.19(-3.61,3.99)$ & $-0.48(-5.32,4.36)$ & $0.75(-3.67,5.17)$ & $0.07(-4.25,4.39)$ \\
\hline
\end{tabular}

Calculations using Bangladesh HIES 2010. Statistically significant differences are indicated by: a $p \leq 0.01, b p \leq 0.05, c p \leq 0.10$.

$\mathrm{p}<0.01)$. Conversely, any-tobacco households reported significantly lower amounts (g/day) of eggs ( $25 \mathrm{vs} 28$, $\mathrm{p}<0.02)$ and oil/fat $(90$ vs $98, \mathrm{p}<0.01)$ compared to non-use households. Consumptions of legumes and beans, meat, milk, vegetables and beverages were not significantly different between the two groups. Further analyses by type of tobacco used revealed similar patterns of differences in food consumption. For instance, compared to tobacco non-use households, smoking-only households consumed significantly higher amounts of cereal grains, vegetables and sugar but significantly lower amounts of eggs and oil/fat.

\section{Adjusted comparison of dietary intake}

We derived adjusted differences in food consumption between tobacco-use and non-use households after controlling for other potential determinants of household food consumption: total household expenditure, household size, household childrenadults composition, place of residence (urban vs rural), geographical region, and presence of any member in the household suffering from chronic disease. The adjusted analysis (Table 3 ) showed that any-tobacco use households consumed significantly lower amounts $(\mathrm{g} /$ day $)$ of milk $(\beta=-17.11, \mathrm{p}<0.01)$

Table 3. Adjusted food group consumption analysis between tobacco-use households and tobacco non-use households

\begin{tabular}{|c|c|c|c|c|}
\hline Food group & $\begin{array}{l}\text { Any tobacco } \\
\beta(95 \% \text { CI })\end{array}$ & $\begin{array}{l}\text { Smoking only } \\
\beta\left(95^{\circ} \text { C CI }\right)\end{array}$ & $\begin{array}{l}\text { Smokeless only } \\
\beta(95 \% \text { CI })\end{array}$ & $\begin{array}{c}\text { Dual tobacco } \\
\qquad \beta(95 \% \mathrm{CI})\end{array}$ \\
\hline Cereal grains & $152^{\mathrm{a}}(121,184)$ & $117^{\mathrm{a}}(79.33,154)$ & $120^{\mathrm{a}}(80.35,159)$ & $256.14^{\mathrm{a}}(209.57,302.72)$ \\
\hline Legumes and beans & $0.32(-3.34,3.99)$ & $0.85(-3.31,5.02)$ & $-1.03(-5.42,3.37)$ & $3.24(-2.08,8.55)$ \\
\hline Fish & $-4.35(-11.69,2.98)$ & $-5.64(-13.59,2.32)$ & $0.01(-8.90,8.92)$ & $-0.73(-9.91,8.44)$ \\
\hline Meat & $-1.65(-9.10,5.80)$ & $-5.28(-15.66,5.11)$ & $5.83(-2.64,14.30)$ & $-4.77(-14.46,4.91)$ \\
\hline Milk & $-17.11^{\mathrm{a}}(-29.18,-5.04)$ & $-20.82^{\mathrm{a}}(-35.42,-6.22)$ & $-7.89(-23.57,7.79)$ & $-17.81^{\mathrm{c}}(-32.76,-2.86)$ \\
\hline Fruit & $5.55(-12.09,23.20)$ & $0.43(-21.41,22.27)$ & $16.01(-5.90,37.92)$ & $4.26(-20.89,29.41)$ \\
\hline Vegetable & $0.34(-28.67,29.35)$ & $5.34(-26.93,37.60)$ & $-4.00(-36.51,28.52)$ & $20.71(-17.26,58.67)$ \\
\hline Sugar & $8.16^{\mathrm{a}}(4.13,12.20)$ & $5.65^{b}(0.48,10.82)$ & $7.67^{\mathrm{a}}(3.27,12.07)$ & $12.86^{\mathrm{a}}(6.82,18.90)$ \\
\hline Eggs & $-1.60(-3.76,0.57)$ & $-1.54(-3.48,0.41)$ & $-0.85(-4.48,2.78)$ & $-0.96(-5.15,3.22)$ \\
\hline Oil/fat & $-10.30^{\mathrm{a}}(-12.94,-7.66)$ & $-4.69^{b}(-7.65,-1.74)$ & $-10.30^{\mathrm{a}}(-13.31,-7.29)$ & $-13.71^{a}(-17.01,-10.41)$ \\
\hline Beverage & $-0.26(-3.69,3.18)$ & $0.91(-3.31,5.13)$ & $-0.84(-4.89,3.21)$ & $0.20(-3.73,4.13)$ \\
\hline
\end{tabular}

Calculations using Bangladesh HIES 2010. Coefficient $\beta$ for respective household categories by tobacco use represents adjusted mean difference in food consumption ( $g /$ day/household) from tobacco non-use households. Coefficients for the control variables, including total household expenditure, household size, household children-adults composition, place of residence (urban vs rural), geographical region, and presence of any member in household suffering from chronic disease, are not reported in the Table. Statistically significant differences are indicated by: ${ }^{\mathrm{a} p} \leq 0.01,{ }^{\mathrm{b}} \mathrm{p} \leq 0.05$, and ${ }^{\mathrm{c}} \mathrm{p} \leq 0.10$. 
and oil/fat $(\beta=-10.30, p<0.01)$ but higher amounts of cereal grain products $(\beta=152, \mathrm{p}<0.01)$ and sugar ( $\beta=8.16, p<0.01)$ compared to non-use households. No statistically significant differences were seen in consumption of legumes and beans, fish, meat, fruit, vegetable, eggs, and beverages.

Similar associations were seen within the subcategories of tobacco use as well. Smoking-only households consumed lower amounts of milk ( $\beta$ $=-20.82, \mathrm{p}=0.01)$ and oil/fat $(\beta=-4.69, \mathrm{p}<0.01)$, but higher amounts of cereal grains $(\beta=116.51$, $\mathrm{p}<0.01)$ and sugar $(\beta=-5.65, \mathrm{p}<0.01)$ compared to non-use households. Smokeless-only households consumed significantly lower amount of oil/fat $(\beta=-10.30, p<0.01)$ but higher amount of cereal grains $(\beta=119.59, \mathrm{p}<0.01)$ compared to non-use households. Similar patterns were observed for dual-tobacco use households but with even greater disparities in consumption of cereal grains, sugar, and oil/fat.

\section{DISCUSSION}

This study provides one of the first reports addressing the relationship between household food and tobacco consumption in a developing country, using nationally representative data. Our findings suggest significant food consumption differences among tobacco-use households compared with non-use households, exhibited by their higher consumption of cereal grains and sugar and lower consumption of milk, and oil/ fat. While research from developed countries has found lower consumption of plant-based foods and higher consumption of dietary fat and meat among tobacco users, our study found higher consumption of cereal grains and sugars (inexpensive sources of calories) and lower consumption of milk that could provide important nutrients in a very low-resource environment. Additionally, in contrast with previous research findings from developed countries, we did not find statistically significant differences for fruit and vegetable consumption in relation to tobacco consumption. However, the household level of the analyses did not allow us to assess whether fruit and vegetable intake varies among tobacco users and non-users within the household. Further research is needed to address and evaluate food distribution within the households in relation to individual tobacco-use behavior. Consistent with previous findings from developed countries, tobacco users appear to have a poorer quality diet than non-users, although the specific consumption patterns differ.

Our results provide support for the conclusion that households that purchase tobacco may be diverting funds that would otherwise be spent on more costly food items, such as milk, and replacing those calories with inexpensive cereal grains ${ }^{12}$. A separate analysis of this dataset found that within food consumption categories, cereals constituted the largest share of expenditure ( $>40 \%$ of total food expenditure) among tobacco-use households ${ }^{9}$. Husain et al. ${ }^{18}$ recently (2018) reported that household consumption of tobacco competes with other household expenditures; while tobacco-use households spent more on food and medical items, compared with nonuse households, they spent less on clothing, housing, education, transportation, and communication. As previously proposed ${ }^{19,20}$, household spending on tobacco may contribute to a vicious 'cycle of poverty', with tobacco use contributing to a poorer diet, diverting funds from other necessities and in turn exacerbating socioeconomic status. The relationship between tobacco use and poverty has been observed in many countries and across different income levels; even within LMICs, tobacco use tends to be higher among the poorest groups of the population ${ }^{20}$.

\section{Limitations and strengths}

This study has some limitations. Given the structure of the survey used, the unit of analysis in this study is the household, not the individual; therefore, information was not available on how food was distributed among members of the household and how this distribution may have differed between households. We also do not know who or how many individuals within the household use the tobacco products that were purchased and reported at the household level. Additionally, while the food consumption categories used in this study reflect major sources of macronutrients, they may not provide precise representation of micronutrients. The HIES survey does not collect data on alcohol or other drug use, and thereby we are unable to assess any association between tobacco and alcohol or other drug substances. An interaction between tobacco use, alcohol and drug substances could potentially influence diet, through 
biological and economic factors ${ }^{21}$. Additionally, collecting data on age of children and breastfeeding in future studies could be important to understand the potential influence of these factors on the observed significantly lower milk intake among tobacco-use households.

Nevertheless, the consistent pattern of differences in household-level food consumption in relation to tobacco use that emerged from this study constitutes an important finding with implications for public health.

\section{CONCLUSIONS}

Our findings demonstrate that use of tobacco is associated with poorer food consumption, and the effects are likely to impact on all household members, including those members not using tobacco. Thus, there is a need to address nutritional gaps concurrently with the pervasive tobacco epidemic in Bangladesh and other developing countries. Further research is needed to understand the complex interplay between tobacco and diet in low-income countries, including studies with individual-level data and in other low-resource settings. Such work could play an important role in developing strategies to address poor diet, malnutrition and tobacco use in developing countries. Additionally, reducing tobacco consumption in developing countries may help contribute towards achieving the post-2015 development goal of eradicating extreme poverty and hunger.

\section{REFERENCES}

1. de Castro JM, Taylor T. Smoking status relationships with the food and fluid intakes of free-living humans. Nutrition. 2008;24(2):109-119. doi:10.1016/j.nut.2007.10.005

2. Morabia A, Wynder EL. Dietary habits of smokers, people who never smoked, and exsmokers. Am. J Clin. Nutr. 1990;52(5):933-937. doi:10.1093/ajcn/52.5.933

3. Palaniappan, U., Jacobs, S. L., O'Loughlin, J., and GrayDonald, K. Fruit and vegetable consumption is lower and saturated fat intake is higher among Canadians reporting smoking. J Nutr., 2001, 131: 1952-1958.

4. Phillips EL, Arnett DK, Himes JH. Differences and trends in antioxidant dietary intake in smokers and non-smokers, 1980-1992: the Minnesota Heart Survey. Ann. Epidemiol. 2000;10(7):417-423. doi:10.1016/s1047-2797(00)00064-8

5. Subar AF, Harlan LC. Nutrient and food group intake by tobacco use status: the 1987 National Health Interview Survey. Ann. N. Y. Acad. Sci.1993;686:310-321. doi:10.1111/j.1749-6632.1993.tb39193.x

6. Ma J, Hampl JS, Betts NM. Antioxidant intakes and smoking status: data from the continuing survey of food intakes by individuals 1994-1996. Am. J Clin. Nutr. 2000;71(3):774-780. doi:10.1093/ajcn/71.3.774

7. Kvaavik E, Meyer HE, Tverdal A. Food habits, physical activity and body mass index in relation to smoking status in 40-42 year old Norwegian women and men. Prev. Med. 2004;38:1-5. doi:10.1016/j.ypmed.2003.09.020

8. Padrao P, Lunet N, Santos AC, Barros H. Smoking, alcohol, and dietary choices: evidence from the Portuguese National Health Survey. BMC. Public Health. 2007;7(1):138. doi:10.1186/1471-2458-7-138

9. Husain MJ, Virk-Baker M, Parascandola M, Khondker BH, Ahluwalia IB. Money gone up in smoke: the tobacco use and malnutrition status in Bangladesh. Ann Glob Health. 2017; 82(5):749-759. doi:10.1016/j.aogh.2016.07.005

10. John RM. Crowding out effect of tobacco expenditure and its implications on household resource allocation in India. Soc. Sci. Med. 2008;66(6):1356-1367. doi:10.1016/j.socscimed.2007.11.020.

11. John RM, Ross H, Blecher E. Tobacco expenditures and its implications for household resource allocation in Cambodia. Tob. Control. 2012;21(3):341-346. doi:10.1136/tc.2010.042598

12. Pu CY, Lan V, Chou YJ, Lan CF. The crowding-out effects of tobacco and alcohol where expenditure shares are low: analyzing expenditure data for Taiwan. Soc. Sci. Med. 2008;66(9):1979-1989. doi:10.1016/j.socscimed.2008.01.007

13. World Health Organization. Global Adult Tobacco Survey: Bangladesh report 2009. Dhaka, Bagngladesh: Country Office for Bangladesh; 2009.

14. Food and Agriculture Organization of the United Nations, International Fund for Agricultural Development World Food Programme. The state of food insecurity in the world 2015: meeting the 2015 international hunger targets: taking stock of uneven progress. Rose, Italy: Food and Agriculture Organization of the United Nations; 2015.

15. Bangladesh Bureau of Statistics. Report of the Household Income \& Expenditure Survey 2010. Bangladesh Bureau of Statistics. Statistics Division, Ministry of Planning; 2011.

16. World Bank. Bangladesh: household income and expenditure survey: key findings and results 2010 . Washington, D.C.: World Bank; 2016.

17. StataCorp.2015. Stata Statistical Software: Release 14. College Station, TX: StataCorp LP; 2016.

18. Husain MJ, Datta BK, Virk-Baker MK, Parascandola $\mathrm{M}$, Khondker BH. The crowding-out effect of tobacco expenditure on household spending patterns in Bangladesh. Plos one. 2018;13(10): e0205120. doi:10.1371/journal.pone.0205120

19. U.S. National Cancer Institute and World Health 
Organization. The Economics of Tobacco and Tobacco Control. National Cancer Institute Tobacco Control Monograph 21. NIH Publication No. 16-CA-8029A. Bethesda, MD: U.S. Department of Health and Human Services, National Institutes of Health, National Cancer Institute; and Geneva, CH: World Health Organization; 2016.

20. World Health Organization. Tobacco and poverty: A vicious Circle. WHO/NMH/TFI/04.01. Tobacco Free Initiative, World Health Organization, 2004. http://www. who.int/tobacco/communications/events/wntd/2004/ en/wntd2004_brochure_en.pdf. Accessed September 19, 2017.

21. Padrao P, Silva-Matos C, Damasceno A, Lunet N. Association between tobacco consumption and alcohol, vegetable and fruit intake across urban and rural areas in Mozambique. J Epidemiol. Community Health. 2011;65(5):445-453. doi:10.1136/jech.2009.099440

CONFLICTS OF INTEREST

The authors have completed and submitted the ICMJE Form for Disclosure of Potential Conflicts of Interest and none was reported.

\section{FUNDING}

There was no source of funding for this research.

AUTHORS' CONTRIBUTIONS

All authors participated in the development of the study plan and analysis, interpretation of results, and the writing of the paper.

PROVENANCE AND PEER REVIEW

Not commissioned; externally peer reviewed. 